\title{
Pedagogy of the Front Float: Dialogue and Aquatics Programming in Taloyoak, Nunavut
}

\author{
AVA C. BAKER ${ }^{1}$ and AUDREY R. GILES ${ }^{2}$
}

(Received 7 May 2007; accepted in revised form 29 October 2007)

\begin{abstract}
We examine the first author's experiences with aquatics programming in Nunavut through a Freirian lens, arguing that one can use Paulo Freire's ideals of dialogue and collaboration to recognize recreation as a mode of social oppression and to offer ways to disrupt this oppression. Though Freire's work is almost 40 years old, his theoretical contributions have not yet been fully realized within the recent post-colonial context surrounding physical activity, and particularly aquatics programming, in Canada's North. Using this critical inquiry approach, we suggest that programmers can make aquatics offerings more collaborative and culturally relevant by recognizing the cultural and geographical context of northern communities, dialoguing with community members about aquatics programs, and adapting southern-based programs to the northern context.
\end{abstract}

Key words: Nunavut, Northwest Territories aquatics program, drowning, Inuit, health, physical activity

RÉSUMÉ. Nous nous penchons sur les expériences du premier auteur en matière de programmation aquatique au Nunavut en empruntant l'approche de Freire, soutenant ainsi qu'on peut recourir aux idéaux de Paulo Freire en matière de dialogue et de collaboration pour reconnaître les loisirs en tant que mode d'oppression sociale et présenter des moyens d'interrompre cette oppression. Même si l'œuvre de Freire remonte à près d'une quarantaine d'années, ses contributions théoriques n'ont toujours pas été entièrement réalisées dans le contexte post-colonial récent en matière d'activité physique, et surtout de programmation aquatique dans le Nord canadien. En nous appuyant sur cette approche d'enquête critique, nous soutenons que les responsables de la programmation peuvent faire en sorte que les options du domaine aquatique soient davantage coopératives et pertinentes du point de vue culturel en tenant compte du contexte culturel et géographique des collectivités du Nord, en dialoguant avec les membres de la collectivité au sujet des programmes aquatiques et en adaptant les programmes du sud au contexte du nord.

Mots clés : Nunavut, programmes aquatiques dans les Territoires du Nord-Ouest, noyade, Inuit, santé, activité physique

Traduit pour la revue Arctic par Nicole Giguère.

\section{INTRODUCTION}

This paper is written primarily as a first-person narrative in the voice of the first author, who conducted all the fieldwork. The second author assisted with the conceptual development of the research project as well as the analysis.

I first went to Taloyoak, Nunavut, to work as aquatic director in the summers of 2004 and 2005. In May 2006, I prepared to return to the community as aquatic supervisor, but this time with the additional role of ethnographer. The first time that I traveled to Taloyoak, I experienced deep culture shock and was unprepared for my introduction-or lack thereof - to the community. The orientation program for aquatic supervisors working in the North had been eliminated many years ago, a victim of cutbacks. I thus found myself the only lifeguard in this remote town, taking over after several years of other southern lifeguards who had worked in the hamlet for a year and then left. There was no continuity or connection to previous years, save for some final pool reports. I found that despite a number of recent local drowning deaths, swimming lessons were poorly attended and some programs that I tried to implement did not attract community participation. Certainly, Taloyoak provided a stark contrast to the successful swimming pool programs that I had facilitated in the South, prompting me to pause and to give thought to the reasons why my previous success in southern programming had not translated into success in Canada's North and to conduct research with Taloyoakmiut. Here, the example of northern aquatic programming is used to argue that the ideals of dialogue and collaboration articulated by Brazilian educator Paulo Freire (1970) allow us to recognize recreation as a mode of social oppression and can also be employed to disrupt this oppression. Further, we offer an example of what meaningful dialogue might look like in the somewhat unusual setting of aquatic programming in a land of ice, snow, and the midnight sun.

The Northwest Territories (NWT) — and now NunavutAquatics Program has existed in a variety of forms since its inception in 1967 (Giles and Baker, 2007; Giles et al., 2007). Beginning in the late 1960s, permanent and temporary pools were built in communities across the NWT, and

\footnotetext{
${ }^{1}$ Faculty of Medicine, Health Sciences Centre, University of Calgary, 3330 Hospital Drive NW, Calgary, Alberta T2N 4N1, Canada

${ }^{2}$ School of Human Kinetics, University of Ottawa, 125 University Street, Ottawa, Ontario K4A 3K3, Canada; agiles@uottawa.ca

(C) The Arctic Institute of North America
} 
waterfronts were established in some communities where water was warm enough for swimming during the summer. After Nunavut was created in 1999, the new territory took responsibility for aquatics programming within its boundaries. While the swimming pool program has continued as one of the most successful recreation programs in the territory, it experiences a variety of challenges each year, ranging from a high staff turnover to facility problems (Giles and Baker, 2007; Giles et al., 2007). In spite of these challenges, swimming pools in remote communities in Nunavut and the NWT remain essential components of drowning prevention and active living programs.

Even after 40 years of aquatics programming, drowning rates in Canada's territories are much higher than the national average (NWTHSS, 2004). During the 1990s, the drowning rate for the NWT was an astonishing 10 times the national average (Waldram et al., 2006:105). Furthermore, the figures showed that aboriginal people in the NWT are more likely to drown than nonaboriginal people, demonstrating this population's heightened vulnerability (NWTHSS, 2004). The anomalous drowning rate among aboriginal people in the North is one of the contributing factors that cause the national ratio of age-standardized mortality rates due to injury in Canada to be three times as high among aboriginal people as in the rest of the population (Waldram et al., 2006). To understand the factors that contribute to such a disproportionate number of aboriginal deaths by drowning, particularly in northern communities, we examine aquatics programs in the North, the very programs that are intended to decrease accidental waterrelated fatalities.

The lens through which we examine northern aquatic programs is influenced by the work of Paulo Freire, which is useful in addressing attempts at education-including aquatics education-in colonized and postcolonial populations, such as the Inuit in Taloyoak. In particular, Freire's popular text Pedagogy of the Oppressed (1970) advocates the use of meaningful dialogue and collaboration between the colonizer and the colonized. This is by no means a new idea, as those who adopt participatory action research have emphasized the importance of aboriginal control of resources in aboriginal communities (Israel et al., 1998; Minkler and Wallerstein, 2003). Freire's approach is unique, however, in acknowledging that oppression of the colonized cannot end until the colonizers recognize the ways in which they too are oppressed.

We will demonstrate that aquatics programmers (typically from the South), despite academic awareness of the need for dialogue and communication before and while establishing and implementing programs in northern communities, are oppressed by their southern-based ideals and have ignored emerging best practices in areas such as northern education. We argue that the failure of water safety programmers to adapt to changing social and political contexts has produced shortcomings in aquatic programming that may be contributing to drowning deaths.

\section{SITUATING THE COMMUNITY, ITS RESIDENTS, AND THE RESEARCH}

Taloyoak, Nunavut, located in the Kitikmeot region on the Boothia Peninsula, is the northernmost community $\left(69^{\circ} 33^{\prime} \mathrm{N}, 93^{\circ} 35^{\prime} \mathrm{W}\right)$ on Canada's mainland. According to Statistics Canada (2006), the population of Taloyoak in 2006 was 809 . The community is composed mainly of Inuit, with only 45 non-Inuit residents recorded in 2001. English is the language most used for conducting business in Taloyoak, but more than $60 \%$ of the population reported a first language other than English (Statistics Canada, 2008). Many elders in Taloyoak are monolingual Inuktitut speakers, while many of the children speak very little or no Inuktitut. Overall, the population in Taloyoak is relatively young; in 2001, more than half the community residents (370 of 720) were 19 years old or younger (Statistics Canada, 2008). The Hamlet has only basic amenities: two grocery stores, a school, a health centre, a combined hockey arena and community hall, and a swimming pool.

The Moses Teelktaq Memorial Swimming Pool in Taloyoak, named after a deceased respected elder, was constructed in 1995 and opened on 15 July of that year. According to Scotty Edgerton (pers. comm. 2006), the senior administrative officer for the community, the pool was built in response to safety issues in the community:

The reason that [the swimming pool] was put here is because there are so many safety issues. We don't get rid of the ice here until generally the last week of July or the first week in August, so there's an issue there of safety. You go out there on the ice, and you could end up drowning. The other thing, too, is that it's such cold water here: the water doesn't warm up, and it's really unhealthy for the kids to go and just turn blue in this type of water.

The swimming pool has operated seasonally since 1995 and has been staffed by aquatic directors from southern Canada, who are responsible for hiring and overseeing one or two local pool assistants for the summer's duration. The pool itself is a heated indoor pool, which measures $10 \mathrm{~m}$ long and $5 \mathrm{~m}$ wide. Like many northern pools, it is a shallow-water pool, with a constant depth of approximately $1 \mathrm{~m}$, although the actual depth of the water varies depending on the amount of water delivered by the water truck on any given day. The indoor swimming pool operates during summer, when children are out of school and the warm temperatures make the pool an inviting place to cool off and pass time. The Taloyoak pool is one of seven pools in Nunavut that were open in the 2006 season, and one of just four pools that operated for the full season, as some closed early because of mechanical or staff problems (Driscoll, 2007). Swimming pools in Iqaluit, Cape Dorset, Rankin Inlet, Baker Lake, Arviat, and Cambridge Bay were also open in 2006. 


\section{RECREATION AND COLONIALISM IN CANADA'S NORTH}

Aquatics may not seem like the most appropriate arena for a discussion of colonialism and oppression; however, recreation is an area that reflects an ongoing struggle in the North for aboriginal identity and culture (Paraschak, 1995; Giles, 2005, in press; Giles and Baker, 2007; Giles et al., 2007). Aboriginal people are among the most marginalized citizens in Canadian society, and northern aboriginal peoples in particular face unique challenges. Although many scholars would claim that Canada has entered a "post-colonial" era, the vestiges of colonialism-including loss of identity, disparities in health status, and socioeconomic inequality-are still realities in northern communities and aboriginal communities in general. Certainly, many aboriginal people do not believe that the effects of colonialism faded with the days of the "northern frontier." They suggest instead that many Inuit continue to engage with the remnants of colonialism (Inuit Tapiriit Kanatami, 2007) that permeate all facets of life (including recreation).

According to Johnston et al. (1994:75), "characteristic features of the colonial situation include political and legal domination over an alien society, relations of economic and political dependence and exploitation between imperial power and colony, and racial and cultural inequality." Certainly, the NWT was-and at times still is - treated as a Canadian colony, with Ottawa serving as the administrative base for the NWT until 1967 (Paraschak, 1997). The NWT was long governed by a territorial council composed of southern-based federal civil servants: only after World War II were local residents appointed to the council (Coates and Powell, 1989). In 1974, the NWT Act was finally amended to allow for a fully elected council of NWT residents (Coates and Powell, 1989). Coates (1985:9) argued that the southern territorial administrators, much like other colonial powers, were "physically thousands of kilometres distant, and psychologically even further removed" from the realities of northern life, including recreation (Giles, in press).

The physical and psychological distances between Northerners and Southerners contributed to difficulties in recreation programming. Paraschak (1985:11) noted that "since it is [predominantly southern-born and raised] government workers who establish the programs and services for recreation, very often those programs end up being based on southern Canadian rather than native standards, even though they are created to meet native needs." In her later work, Paraschak (1997) illustrated the possibility of using recreation as a tool of colonial conquest by drawing attention to the Native Sport and Recreation Program, implemented in Canada from 1972 through 1981. Its goal was to introduce a system of recreation that would allow aboriginal people to engage in competition in the same arena as "mainstream" Canadians (Paraschak, 1997). This attempt to promote Euro-Canadian-styled recreation was representative of "an assimilationist process to bring Native people into the mainstream sport system" (Paraschak, 1995:14). Federal funds were used to finance the implementation of so-called "legitimate" forms of sport and recreation, including hockey, basketball, boxing, and other Euro-Canadian sporting practices (Paraschak, 1995).

The NWT Aquatics Program was started in 1967 with the goal of building leadership in aboriginal youth, but over time, an additional emphasis on drowning prevention emerged (Giles et al., 2007). Like the Native Sport and Recreation Program, the Aquatics Program transported southern activities to communities across the NWT and Nunavut. Southern university and college students were imported to train local community members as swimming instructors and lifeguards so that eventually local residents could take over the aquatic supervisor's role. At the same time, it was hoped that emphasis on swimming lessons would decrease the disproportionately high rate of drowning found across the North. Forty years later, however, very few Northerners work in supervisory positions, and the drowning rate in the NWT and Nunavut remains 10 times the national average (Giles et al., 2007).

The blanket dispensation in remote northern communities of an aquatic agenda almost entirely Euro-Canadian in origin and motivation was based on notions of the cultural superiority and authority of Southerners and their programs and activities. Kathryn Youngblut (pers. comm. 2006), a former long-time NWT Aquatics Program coordinator, recounted an experience that illustrates this point beautifully:

These people we did bring up [from Alberta as examiners] just had no concept [of the North] whatsoever... One time in Fort McPherson [during a Bronze Medallion lifesaving award exam] they asked, "What is the first thing that you do when you suspect that someone has hypothermia?" One boy said, "I keep the fire going," and [the examiner] failed him. I fought that right to the Royal Lifesaving Society: I went all the way with it. And we won. I said, "We are in the middle of the [Mackenzie] delta, you know-they live in tents all summer. Of course that's what you do! He keeps his fire going!" "Well," they said, "that's not the answer." I said, "It is the answer for him." But she just wouldn't bend — she wouldn'tbend, nothingno matter what we said to her, she couldn't bend. I went to Alberta and I argued with them and they wouldn't support me. So I went to national and said, "Look, this is stupid, this is exactly the way he should be for his circumstances, because that is what he needs." Anyway he finally got his Bronze Medallion.

The incident shows that marginalization and failure to recognize the legitimacy of northern knowledge resulted in ineffective aquatic programming, which continues to this day.

Giles et al. (2007) argue that aquatic programming in the NWT and Nunavut continue to be hindered not only by the marginalization of local knowledge pertaining to 
hypothermia, but also by the failure to recognize the contributions that local, culturally based understandings of leadership and traditional knowledge could make in an effort to enhance aquatic programming. These authors suggest that such shortcomings could be addressed by creating northern-specific training to enable local residents to run aquatics facilities. While ineffective recreation programming may not seem to be a particularly important area to examine, epidemic levels of Type 2 diabetes (Health Canada, 2001) and disproportionately high rates of drowning among aboriginal Northerners speak to the need for urgent and concerted attention.

\section{CRITICAL THEORY}

After spending several summers in Canada's North, I began to question the ways in which I was delivering aquatics programming and to wonder about the role that I, a person who did not initially incorporate considerations of geography or ethnicity into my swimming lessons and attempts at lifeguard training, played in maintaining unequal power relations and re-inscribing notions of cultural superiority. Was I an oppressor? I began to challenge some of the assumptions that provided the foundation of my approach to aquatic programming and began to contemplate some of the ways in which northern aquatics could be revised to be more culturally appropriate, meaningful, and thus successful, particularly for Taloyoakmiut.

This use of ideas as agents for change led me to use critical inquiry as the conceptual framework for my research. Crotty (1998:157) explains that "critical forms of research call current ideology into question, and initiate action, in the cause of social justice." The outcome of critical inquiry is revolutionary action, or radical change, but this change comes about as a result of dialogue and reflection. Freire (1970:79) influenced the area of critical inquiry by suggesting that the world does not simply evolve, but is transformed by "the action and reflection of men and women upon their world." According to Freire (1970), this action and reflection are a result of the inherent human capacity for creativity: people who conduct research within a critical theory framework do so as creative beings in order to effect change. My goal was to work with community members to promote dialogue and create change in the ways that aquatics programming is both imagined and facilitated in Canada's North.

\section{Dialogue within Critical Research Frameworks}

Several scholars who conduct research in indigenous communities have noted the importance of acknowledging their own perspective in approaching that research and of using the information they acquire to benefit the community members. Wilson (2001) describes indigenous research methodology as being grounded in relationships, and Weber-Pillwax (2001) advocates research that benefits the community. Although research by scholars of any origin could theoretically fulfill such requirements, both Wilson and Weber-Pillwax refer explicitly to indigenous scholars like themselves, and not to non-aboriginal people, when discussing methodology for research in aboriginal communities. This is in part because "while a Eurocanadian might want to use Indigenous frameworks, attempts at such usage could quite justifiably result in concern surrounding the co-optation of Indigenous frameworks by a non-Indigenous scholar" (Giles, 2005:11).

In my dual role as researcher and aquatic supervisor, I had to be aware of my own worldviews, be prepared to challenge my beliefs, and recognize that I approached my research and my job through my middle-class, southernbased, Eurocanadian lenses. It would have been inappropriate for me to approach research or to create aquatic programming claiming to do so from an aboriginal point of view, as I am not aboriginal. Nor do I claim I can fully understand an aboriginal perspective: that would be not only disingenuous, but also an unfortunate example of cultural (mis)appropriation. This is not to say that researchers and aquatic supervisors should not be familiar with and influenced by indigenous methodologies. To the contrary, I follow Paraschak (1996:110), who states, "I cannot present my work from a native perspective; but I can have it 'informed' by my understanding of the native perspective."

In northern social research, dialogue also can be used in combination with other research methodologies, such as participatory action research (PAR). Minkler (2000:192) defines PAR as "research practice that place[s] the researcher in the position of co-learner and put[s] a heavy accent on community participation and the translation of research findings into action." This definition concurs with Freire's ideas of community empowerment and nonimposition. Researchers who engage in Freirian dialogue within the framework of PAR can participate more fully in true collaboration and communication with communities. For example, instead of just hearing community ideas about aquatics programs, they can move that dialogue to action, with resulting changes that both help the community and facilitate the research.

\section{Freirian Dialogue in Principle and Practice}

To address community and cultural needs, outsiders participating in northern recreation as researchers and programmers can employ Freire's (1970) conceptions of oppression and dialogue. According to Freire (1970:89), "dialogue imposes itself as the way by which (people) achieve significance as human beings. Dialogue is thus an existential necessity.... this dialogue cannot be reduced to the act of one person's 'depositing' ideas in another." Dialogue facilitates a framework through which researchers and programmers alike can engage in community development and participate in the implementation of more specific community-based programs. 
Dialogue is contrary to oppression, which can be described as "any situation in which 'A' objectively exploits ' $\mathrm{B}$ ' or hinders his or her pursuit of self-affirmation as a responsible person" (Freire, 1970:55). Oppression in northern aquatics most often occurs in the form of the prescriptive implementation of seemingly legitimate southern-based aquatic programming at a northern facility with little or no consideration for the ethnic, social, or geographical context (Giles, 2001). Freire (1970:91) claims that "every prescription represents the imposition of one [person's] choice upon another, transforming the consciousness of the [person] prescribed to into one that conforms with the prescriber's consciousness." Introducing dialogue as a means to promote successful aquatic programming removes the pressure on the outside programmer to act merely as a product of her or his worldview and personal programming experiences, opening the door to the possibility of engaging the community. Participating in dialogue means that outsiders are no longer the only source of expert knowledge: community members serve as experts, too. Thus, in a dialogical model of aquatics, the oppressor and the oppressed work in conversation to move from the imposition of a mainstream model of aquatics to a model with more cultural and situational relevance.

It would be simplistic to view the outsider only as the oppressor and the community members only as the oppressed. It is important to note that in a Freirian model, the oppressors are also oppressed by their own worldview. Indeed, Freire (1970) does not argue that oppressors must just renounce their own oppressive tendencies. Rather, he contends that "the great humanistic and historical task of the oppressed (is) to liberate themselves and their oppressors as well" (Freire, 1970:44). In my employment in northern aquatics programming, I have been limited by my view of what constitutes an acceptable program or an acceptable teacher. I have been trapped in a web of standards and certifications, and according to Freire (1970), as a member of the oppressive class, I am unable to free either others or myself. Further, in the case at hand, to consider the Inuit as purely an oppressed people ignores their agency and capabilities. Aquatic programmers must acknowledge and act with the expectation that community members have the ability and the resourcefulness to address challenges, and that learning, like liberation, needs to be bidirectional. Employing this approach requires the complete abandonment of paradigms of indigenous people as inferior, and requires the programmer-and the researcher, for that matter-to approach communities in a spirit that both recognizes cultural biases (including racism) and is willing to work beside members of a particular cultural group despite ingrained prejudice.

Moving beyond a view that considers Euro-Canadian approaches to aquatics as "right" and northern approaches as "wrong" requires a critical view of current programming. Paraschak (1982:429) argues that "people's needs in northern communities must determine the direction to be taken, for it is their lives which will ultimately be affected by the decisions chosen." Thus it falls to the programmers to work with community members to find a way to uncover and address those needs. This might occur through dialogue and through what Freire (1970) terms "solidarity" with the oppressed: that is, "fighting at their side to transform [their] objective reality" (Freire, 1970:50). Preparing myself to engage in true dialogue and solidarity, I began to understand that aquatics in Nunavut could be re-sculpted to reflect the agency of Northerners, which Paraschak (2000:11) describes as "their relative ability to shape the world within boundaries created by others as well as by themselves."

\section{Including Culture and Tradition in Dialogue}

A critical approach to aquatics programming in Nunavut must make culture and tradition central to any programming because it is in everyday activities, such as swimming lessons, that the "struggle between different meaning and value systems" (Hall, 1991:32) - in this case, the struggle between Euro-Canadian and Inuit value systemstakes place. While it is correct that Inuit people did not traditionally include swimming lessons, complete with front floats and treading water, as part of their cultural practices, it is not a prerequisite of a culturally relevant program that it specifically incorporate only traditions that existed 500 years ago. This sort of view propagates the myth that indigenous people are frozen in time and remain static in their culture. It also denies the relevance of aquatic programming in meeting the current northern need to reduce drowning rates. It is equally unreasonable for a northern aquatics program to be externally created and administered as an entirely Eurocentric program; too often, both the program contents and other aspects such as scheduling fail to recognize the unique lifestyle of northern indigenous people. For example, many aquatics programs in southern Canada run during the morning and early afternoon. But in northern communities in summer, when there are 24 hours of sunlight a day, many pre-teens and teenagers stay up all night and sleep during the day, so morning programs are unpopular (Giles et al., 2007). Such programs are thus not as effective as those created through dialogue and collaboration with potential participants. While many school-based educators have already learned this lesson, it has not been extended to the NWT and Nunavut aquatics programs. Cutbacks to training and orientation programs, along with the seasonal and temporary character of summer aquatics programming, have contributed to failures in attempts at dialogue.

\section{METHODOLOGY AND METHODS}

To approach aquatics and drowning prevention in Nunavut from a dialogical, Freirian perspective, I first ensured that I was entering the community through the proper channels and met the requirements for conducting research in Canada's far North. Community consultations 
in the Hamlet of Taloyoak allowed community input into the research project and resulted in permission from the Hamlet to proceed. I returned to Taloyoak in May of 2006, embracing my dual role as researcher and aquatics supervisor, and immersed myself in participant observation. Fetterman (1998) explains that through participant observation, researchers can include participation of people with whom research is being conducted, while attempting to keep a professional distance to facilitate unbiased data recording. My previous association with the community as an aquatic supervisor was helpful, as we had already developed considerable rapport. On my return to Taloyoak, I met with the local junior high and high school classes to solicit ideas on what programs they would like to see run at the swimming pool that summer. This experiment in dialogue required me to sacrifice my own aquatic agenda, which I had honed over the past several years, to better address the community's needs. I was initially unsure of the input I would receive, but the students' enthusiasm, the quantity and quality of ideas, and their sense of humour quickly put me at ease. Although I seriously considered most of their suggestions, one class's light-hearted proposal to arrange seal hunting in the swimming pool did not come to fruition.

I also conducted semi-structured interviews. Participants were located through purposeful and snowball sampling, or through their prior involvement in aquatics programs as staff or parents. A trained interpreter resident in Taloyoak assisted in all interviews with monolingual Inuktitut speakers. In total, I interviewed 19 Taloyoak residents, 13 women and 6 men, in three age categories: 18-30 ( 1 woman, 2 men), 30-50 ( 2 women), and over 50 (10 women, 4 men). The over-representation of women in the interview group may reflect the fact that in the summer many of the elders, particularly men, are out on the land.

The interviews were open-ended and semi-structured to allow participants to have input into their direction. The questions focused on traditional approaches to water and water safety, as well as current experiences with swimming in the community. For example: Have you ever gone to the swimming pool here? Why do you think Nunavut has one of the highest drowning rates in Canada? What do you think could be done to prevent drowning in Taloyoak? Do you think that it should be people from Taloyoak teaching about water safety, people from the South, or both? Is it important to you to have people from Taloyoak work at the swimming pool? What kind of safety precautions do you take when you are going to be around the water? During a return visit in February 2007, I gave all participants transcripts of their interviews and discussed the preliminary findings with community members in order to develop them further.

\section{RESULTS}

Although various topics were covered in the interviews and investigated through participant observation, I will focus here on results pertaining to the ways in which dialogue can strengthen approaches to drowning prevention, swimming lessons, the training of aquatics staff, and the creation of water safety programs.

\section{Drowning and the Role of Swimming Lessons in Taloyoak}

Dialogue is important in considering possible solutions to the disproportionately high drowning rates in the North. One obvious reason for the high drowning rate is the omnipresence of lakes, rivers, and the ocean in Nunavut. In Taloyoak, bodies of water are involved in the operation of the town, from the daily pumping of water from Water Lake for treatment at the small water plant, to daily travel over water by snowmobile, to any number of subsistence activities involving water, such as fishing and seal hunting. Another factor contributing to the high drowning rate is that many people in the community have little or no experience in-as opposed to on-the water and do not know how to swim. Bernadette Uttaq (pers. comm. 2006), an elder from Taloyoak, explains: "Elders have never been taught how to swim, so they never passed it down to the younger generation." Indeed, in the three summers I was in Taloyoak, only five elders swam in the pool. They came in 2004, when we hosted an "Elders' Day" in collaboration with the home care nurse. Instead of being taught to swim when they were young, most of the elders that I interviewed were told to stay away from the water. Some of the interviewees had been to the pool to experience immersion in a swimming pool, but many expressed regret that they had not learned to swim and were unable to pass that information on to their children and grandchildren. Listening to community members' ideas about why drowning rates remain high in the North helped me to understand what they consider the root of the problem and to engage creatively in finding solutions.

When asked why they thought Nunavut had one of the highest drowning rates in Canada, many participants cited the lack of swimming lessons. Elder Peter Peetooloot (pers. comm. 2006) said, "Swimming lessons and water safety, if they were being taught in Nunavut, there would be less drowning." Health Canada's First Nations and Inuit Health branch (2001) reports that "northern areas have less access to swimming lessons and lifesaving training," and this contributes to high drowning rates in remote aboriginal communities. Research participants in Taloyoak confirmed that they believed swimming training to be one means by which to reduce the number of drownings in the community. Elder Judas Iqalliruq (pers. comm. 2006) argued that swimming lessons were effective because "that way, if they fall into the water or they fall into the ice, at least they have an idea of how to swim, and how to stay up in the water, instead of just going down."

Despite many community members' belief in the value of swimming lessons, very few children in Taloyoak were participating. In 2004 and 2005, I scheduled swimming lessons, advertised these lessons, and spoke with many of 
the children who frequented the swimming pool about attending lessons. In spite of these efforts, swimming lessons consistently had extremely low attendance, with only about six participants each summer. Pool reports for 1998 and 2002 obtained from the swimming pool also showed low attendance. In a community with at least 370 residents under the age of 19 , the attendance of these few children at swimming lessons could do little toward drowning prevention for the vast majority of this population.

\section{Dialogue in Water Safety}

Research participants who were asked the question, "Do you think that it should be people from Taloyoak teaching water safety, people from the South or both?" unanimously agreed that a combination of knowledge from local community members and an external aquatic director was the best way to teach water safety in Taloyoak. This question itself was developed during a semi-structured interview with David Igutsaq, an elder who stressed the need for local involvement in teaching, and the concept was incorporated into subsequent interviews. Betsy Ashevak (pers. comm. 2006) clearly articulated the need for balance in water safety instruction: "I would rather see [the teaching] combined. [Our ancestors] were never taught how to swim and they didn't have any idea how to swim. [Nevertheless], the elders survived in this very cold climate and they would know more about the cold climate [than someone from the South]."

Many community members emphasized that to enhance water safety, elders' knowledge of the land and how to survive in extreme weather conditions should be coupled with knowledge derived from a Eurocanadian perspective. As Peter Peetooloot (pers. comm. 2006) stated:

I'd like to see somebody from down South that knows first aid and knows how to swim and knows about water safety [working here], and I also would like to see a person from the local community who [has] experienced falling in the water, who is experienced about Inuit tradition, who knows about the water... The Inuit tradition and the modern tradition together might make a big difference, so it would be better to have them both. When people start learning, they could know how to survive in both ways.

Similarly, one of the suggestions for ice safety that I heard repeatedly from the elders was to carry a knife (along with conventional boat safety equipment) while travelling on the ice. Lena Kingmiatuq (pers. comm. 2006) explained, "I always tell my son if he goes out to at least have a knife, so if he falls into the water he has a better chance of surviving if he stabs the ice, instead of floating away."

\section{Pool Staff: Local or Southern?}

One of the most immediate resources for water safety is the pool staff. Community opinions on the hiring of pool staff were assessed through the question, "Is it important to you to have people from Taloyoak work at the swimming pool or not?" Although one might have expected the majority opinion in Taloyoak to mirror that of Fort Simpson, NWT, where participants proposed that the best staffing situation for northern programs is to have locally trained aquatics staff (Giles et al., 2007), interviewees in Taloyoak had a much wider range of opinions on staffing of the swimming pool and viewed dialogue as a means to provide the most effective water safety programs in the community. For example, although many community members supported the idea of having locally trained staff, some interviewees supported the idea of having external staff entirely.

Some reasons for supporting the hiring of a non-local aquatic coordinator were that it was beneficial to have an "outside interest that brings in a different [perspective]" (S. Edgerton, pers. comm. 2006) and that imported aquatic directors "wouldn't know whose kids are whose, so they would treat them fairly" (P. Peetooloot, pers. comm. 2006). Conversely, participants who thought that the aquatic supervisor should be a local person argued that local pool staff could "teach other people in the next generation" (Anonymous, pers. comm. 2006) and that local employees would be more likely to be bilingual in English and Inuktitut (L. Kingmiatuk, pers. comm. 2006). However, most participants did not have a strong opinion either way. Many interviewees stressed the importance of having qualified pool staff, regardless of their origin. For example, Mary Karoo (pers. comm. 2006) said:

It doesn't matter to me whether it is a person who comes from this community or if the person comes from the South. The most important thing is that the person knows what they're doing about safety, about safety instruction and the person that is certified about the pool.

Despite the wide range of opinions about whom the Hamlet should employ to run the swimming pool, participants unanimously expressed the need for community members and the aquatic director to work together to provide the best programs for the community.

\section{DISCUSSION}

Interviewees' expression of a need for communication and collaboration in aquatics programming in Taloyoak has several implications for aquatics programmers and researchers in recreation. First of all, both must recognize the northern communities' geographic and cultural contexts to grasp community members' experience well enough to create appropriate drowning prevention programs. Secondly, aquatics programmers must collaborate with community members in creating all aquatics programs, from water safety lessons to open or public swim times. Finally, including dialogue in northern research propels researchers 
to engage the community in conceptualizing ways to adapt a southern-based program to a northern context.

\section{Dialogue and Drowning Prevention}

The statistics alone understate the seriousness of having insufficient or inappropriate aquatic programming in Nunavut. In a small community like Taloyoak, with strong family ties, a drowning death has intense ramifications. As Elder David Igutsaq (pers. comm. 2006) noted, "I just think it's the saddest thing to lose a family [member] in the water. To think that a couple of hours ago my kids were running around laughing, and now they're gone." In order to better serve communities, programmers and researchers must recognize the unique bearing that drowning deaths have in northern communities; they must approach community members as equals and engage in dialogue with them.

Across Canada, aboriginal people are far more likely to drown than non-aboriginal people, which can be explained in part by the proportionally greater time that they spend on or around the water (Health Canada, 2001). Despite the fact that research participants in Taloyoak believe swimming lessons to be an effective method of preventing drowning, enrolment in swimming lessons in Taloyoak remains low. My first summer in Taloyoak was just a few months after two local boys had fallen through the ice and drowned; yet contrary to my own expectations, enrolment in swimming lessons did not increase significantly. A variety of factors may explain the apparent lack of participation in swimming programs even after such a tragedy in the community.

My research findings indicate that one factor contributing to the low enrolment is that residents have not been convinced that swimming lessons in their current form are effective drowning prevention measures. In Taloyoak, it may be that aquatic programs taught in a pool one meter deep, which do not address an Arctic environment and are administered by a southern-based stranger who has no experience on the local waters, fail to connect swimming lessons and survival in the deep, frigid Arctic waters in the minds of community members. Many elders expressed the need to collaborate and combine southern and Inuit knowledge to make swimming lessons and lifesaving training effective. Water safety information taught in Taloyoak has been largely irrelevant because we programmers have relied on our own perceived southern-derived expertise and have thus been unwilling to ask what Taloyoak residents want. We have simply assumed that we knew what the community needed. This example of a colonial attitude of superiority suppresses not only community-generated ideas, but also the programmer's ability to expand her own education to include other ways of knowing.

It was tempting for me to see relying on a knife for ice safety as a failure to take sufficient safety precautions, an indication of my unwillingness to give equal weight to Inuit knowledge of water safety and my preference for written, seemingly more "legitimate" materials. A number of elders commented on the written nature of Eurocanadian knowledge. Bernadette Uttaq (pers. comm. 2007) commented: "With the white person it's always written on paper, but with the Inuit knowledge...[it] is inside me. I memorized it and it's inside me, not all on a piece of paper, so I know for sure, like a fact." It was important for me to recognize my own tendency to hold written knowledge as verifiable - and thus more valuable than orally transmitted knowledge.

Recreation and aquatic programming must recognize the unique situation of northern communities and their residents to plan and implement better water safety programs (which include boat and ice safety), rather than falling victim to the mindset that safety information can be standard across the country, regardless of cultural or community needs. Southern-based programmers must be liberated from the idea that they are always the experts in water safety. One way of beginning this process is to talk to elders and other community members about water and ice safety and have their input into programs. Ideally, southern-based programmers would help facilitate programs where their knowledge is coupled with local ice and water safety knowledge and transferred directly from local experts to other community members. After a training period, local people could then take over the program themselves. Additionally, residents who help to create drowning prevention programs through dialogue may have a more vested interest in the programs - and therefore may be more likely to attend. Certainly, the collaboration between southern staff and northern residents must demonstrate a bidirectional willingness to learn, instead of southern aquatics programmers' attempting to deposit information into what they often view as apparently safetydeprived Inuit.

\section{Dialogue and Aquatics Programmers}

Research participants' responses regarding the hiring of external aquatic directors in Taloyoak indicated that many were willing to engage in dialogue with programmers to create more culturally based aquatic programs. Elders' emphasis on collaboration and cooperation between nonresidents and residents revealed not only a willingness to connect traditional knowledge with new information, but also a desire to do so. In a community like Taloyoak, where many community members strongly advocate partnerships that bridge two systems of understanding, it is the aquatic director's responsibility to facilitate the exchange of ideas that will lead to improved programming.

Creating programs based on dialogue with community members often means adapting to the surrounding culture. In aquatics, this amounts to a willingness to experiment with programming and flexibility in thinking about aquatic activities based on the community's needs, giving up one's own agenda(s) in favour of the community's. For example, in the midst of my attempt to facilitate dialogue in Taloyoak in 2006, I had what I thought was a great idea: to run an 
elders' program incorporating social time, basic swimming skills, and aquafit; however, no one attended. Peter Peetooloot (pers. comm. 2006) explained: "When the swimming pool is open, that's when all the adults and the elders go out on the land. My wife and I would rather be out on the land than swimming." The time that I had scheduled for the elders' swim would have been better used for different programming.

I could have avoided that failure by engaging in dialogue with community members beforehand and trusting their input and feedback. The result of this lapse contrasted with the success that collaboratively designed programs enjoyed, showing the need for consistent, ongoing dialogue. In 2006, we also started free, drop-in lessons at the pool. These lessons, which did not require registration, were much better attended, with up to eight participants in lessons several times a week. To have lessons held so informally, without registration or badges, went against what I had been taught in my water safety instructor courses about the need for structure and organization. However, through my attempts at dialogue, I was able to create potentially life-saving lessons that were exponentially more popular than the lessons I had held in previous years and exemplified to me my need to be freed from the idea that the southern way was the "right" way.

Standard swimming lessons or Eurocentric aquatic programs may never be popular in Taloyoak, but programming created by engaging in dialogue with community members can take some cultural practices into account. Thus lessons can be used to teach southern-based swimming techniques-skills identified by research participants as useful in drowning prevention-within the framework of Inuit culture, for the purpose of improving overall water safety skills and building individual and group confidence in local waters.

While incorporating dialogue into aquatics programs, it was important that the entire process engage community members. The junior high classes that I spoke with before planning the pool's summer program suggested having movie nights at the pool. To host movie nights, several students, aged 10-14, volunteered to prepare and sell snacks, collect the money, and supervise the movie watching. I had not, in my previous years as aquatic director, shared such responsibility, particularly with handling money and supervision. The girls who volunteered came up with several suggestions for snacks and helped to purchase everything we needed at the store. They came early to the movie night and stayed very late, sweeping popcorn off the pool deck and helping move equipment. By demonstrating such responsibility, the girls liberated me from my bias about doing things the "right way," and they were able to develop more and more responsibility at subsequent pool events. The overall effect was pool programming that had community members, even young ones, participating on multiple levels, rather than having a single role as swimming participants that separated them from the supervisor and other staff.

\section{CONCLUSIONS}

A dialogical approach to northern research is not a new concept; nevertheless, it is rarely extended to recreation, as it was in this project. Dialogue, as Freire (1970) intended it, serves as a connection between isolated experiences, allowing the outsider, whether aquatics supervisor or researcher, to engage with people who often have different experiences and values, and vice versa. Rather than merely attempting to combine contrasting cultural practices into a superficial façade of inclusivity, meaningful dialogue creates an atmosphere in which oppressed peoples are able to experience a relational connection. The breakdown of discursive confinement through dialogue liberates each party from the constraints of his or her worldview and opens the door for new and creative opportunities in northern aquatics. Inclusion of dialogue in the outsider's experience makes it much more difficult to maintain false preconceptions about indigenous peoples, such as the myths of the "dying race" or the "noble savage" (Hamilton, 2003), because the process is engaging and personal, rather than removed and isolating. This connected experience permits the development of "intense faith in humankind, faith in their power to make and remake, to create and re-create, and faith in their vocation to be more fully human" (Freire, 1970:91). It further permits the development of programming that is culturally and geographically relevant, and thus effective and potentially life-saving.

In engaging in dialogue with the community about aquatic programming, I certainly became one of the major beneficiaries. I had approached Taloyoak in 2004 with a set idea of what aquatics programs should look like and held a limited view of water safety. By the end of the summer of 2006, I could better appreciate different types of knowledge and different conceptions of water safety. I could recognize my own place as both the oppressor and the oppressed and how my narrow view of knowledge had held me back from a wider understanding of water safety and, in turn, limited the aquatics programs I was able to implement. In this new reciprocal relationship, I was able to develop a better understanding of the people with whom I was working, which led to both improved programming and my own personal development and liberation. It is only through dialogue that recreation programmers are able to open themselves up to the community that they serve, allowing that community to make an impact on them and on the programs they facilitate.

\section{ACKNOWLEDGEMENTS}

Funding for this project was provided by a Social Sciences and Humanities Research Council Standard Research Grant, the Northern Scientific Training Program, an Initiation of Research and New Directions Grant from the University of Ottawa, and an Arts and Science Experiential Education Travel Scholarship from 
McMaster University. We thank Rebecca Karoo (research assistant extraordinaire), the Taloyoak swim team, and Sandy Oleekatalik for their contributions. We would especially like to acknowledge Karen McCullough's guidance in the preparation of this manuscript. Finally, our biggest thanks go to our research participants. Qujanamik!

\section{REFERENCES}

COATES, K. 1985. Canada's colonies: A history of the Yukon and the Northwest Territories. Toronto: James Lorimer and Company.

COATES, K., and POWELL, J. 1989. The modern North: People, politics, and the rejection of colonialism. Toronto: James Lorimer and Company.

CROTTY, M. 1998. The foundations of social research. Thousand Oaks, California: Sage Publications.

DRISCOLL, K. 2007. Pool closed until further notice. Northern News Service, January 22. Available online: http:// www.nnsl.com/frames/newspapers/2007-01/jan22_07poo.html.

FETTERMAN, D.M. 1998. Ethnography: Step by step. Thousand Oaks, California: Sage Publications.

FREIRE, P. 1970. Pedagogy of the oppressed [Pedagogia do Oprimido]. Translated by Myra Bergman Ramos. New York: Continuum International Publishing.

GILES, A.R. 2001. (An)other in the (un)making: Participation in sporting opportunities for Aboriginal peoples in Canada. Avante $7(2): 84-91$.

. 2005. A Foucaultian approach to menstrual practices in the Dehcho Region, Northwest Territories, Canada. Arctic Anthropology 42(2):9-21.

—. In press. Beyond 'add women and stir': Politics, feminist development, and Dene games. Leisure/Loisir.

GILES, A.R., and BAKER, A.C. 2007. Culture, colonialism, and competition: Youth sport culture in Canada's North. In: Donnelly, M.K., and Giardina, M.D., eds. Youth culture and sport: Identity, power, and politics. London: Routledge. 161-173.

GILES, A.R., BAKER, A.C., and ROUSELL, D.D. 2007. Diving beneath the surface: The NWT Aquatics Program and implications for Aboriginal health. Pimatisiwin: A Journal of Indigenous and Aboriginal Community Health 5(1):26-49.

HALL, A. 1991. Sport in Canadian society. Toronto: McClelland \& Stewart.

HAMILTON, T. 2003. The representation and appropriation of Indigenous cultures at Ontario summer camps. Pathways: The Ontario Journal of Outdoor Education 15(1):9-15.

HEALTH CANADA. 2001. Drowning prevention initiatives. First Nations \& Inuit health. http://www.hc-sc.gc.ca/fnih-spni/pubs/ injury-bless/drown-noyade_prevention/index_e.html.

INUIT TAPIRIIT KANATAMI. 2007. Our 5000 year heritage. http://www.itk.ca/5000-year-heritage/index.php.
ISRAEL, B.A., SCHULZ, A.J., PARKER, E.A., and BECKER, A.B. 1998. Review of community-based research: Assessing partnership approaches to improve public health. Annual Review of Public Health 19:173-202.

JOHNSTON, R.J., GREGORY, D., and SMITH, D.M., eds. 1994. The dictionary of human geography, 3rd ed. Oxford: Blackwell.

MINKLER, M. 2000. Using participatory action research to build healthy communities. Public Health Reports 115:191-197.

MINKLER, M., and WALLERSTEIN, N. 2003. Community-based participatory research for health. San Francisco: John Wiley.

NWTHSS (NORTHWEST TERRITORIES HEALTH AND SOCIAL SERVICES). 2004. Injury in the Northwest Territories: A descriptive report. Yellowknife: Government of the Northwest Territories.

PARASCHAK, V. 1982. The heterotransplantation of organized sport: A Northwest Territories case study. Proceedings of the 5th Canadian Symposium on the History of Sport and Physical Education. Toronto: University of Toronto Press. 424-429.

- 1985. A look at government's role in recreation in the Northwest Territories. In: Patterson, M.J., Arnold, C.D., and Janes, R.R., eds. Collected papers on the human history of the Northwest Territories. Yellowknife: Prince of Wales Northern Heritage Centre. 11-27.

- 1995. The Native Sport and Recreation Program, 19721981: Patterns of resistance, patterns of reproduction. Canadian Journal of History of Sport 26(2):1-17.

1996. Native Canadians in sport: A clash of cultural values. In: Uche, L.U., ed. North-South information culture: Trends in global communications and research paradigms. Nigeria: Longman Nigeria. 99-113.

1997. Variations in race relations: Sporting events for Native peoples in Canada. Sociology of Sport Journal 14:1-21.

_. 2000. "Recreation North": Continuity and change, 19622000. Paper given at the North American Society for Sport History Conference, 26-29 May, Banff, Alberta.

STATISTICS CANADA. 2006. 2006 community profiles census division: Community highlights for Taloyoak. http://www12.statcan.ca/english/census06/data/profiles/ community/Details Page.cfm?Lang=E\&Geo1=CSD\&Code $1=6208087 \&$ Geo $2=$ PR \&Code $2=62 \&$ Data $=$ Count $\&$ SearchText $=$ Nunavut $\&$ SearchType $=$ Begins $\&$ SearchPR $=62 \& B 1=$ All $\&$ Custom $=$.

-2008. Aboriginal population profile, 2006 census. Ottawa: Statistics Canada.

WALDRAM, J.B., HERRING, A.D., and YOUNG, K.T. 2006. Aboriginal health in Canada, 2nd ed. Toronto: University of Toronto Press.

WEBER-PILLWAX, C. 2001. What is Indigenous research? Canadian Journal of Native Education 25(2):166-174.

WILSON, S. 2001. What is an Indigenous research methodology? Canadian Journal of Native Education 25(2):175-179. 